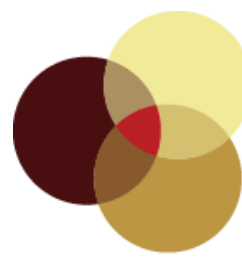

contennporaneity

Vol 1 (2011) | ISSN 2155-1162 (online) | DOI 10.5195/contemp.2011.13

http://contemporaneity.pitt.edu

\title{
Re-Composing the Digital Present
}

\author{
Timothy Barker
}

\begin{abstract}
This paper investigates the temporality that is produced in some recent and historical examples of media art. In exploring works by Janet Cardiff, Dennis Del Favero, and Omer Fast, I use the philosophy of Michel Serres and Gilles Deleuze to understand the convergence of temporalities that are composed in the digital present, as one moment in time overlays another moment. Developing Serres' concept of multi-temporality and Deleuze's philosophy of time and memory into a means to understand the non-linear time presented in these works, I argue that the different compositional strategies enacted by these artists provide the aesthetic grounding to experience "temporal thickness." From here I investigate the interactive digital artworks Frames by Grahame Weinbren and Can You See Me Now? by the artist group Blast Theory. In this investigation, I understand interaction with technology, and the way that it shapes our sensory and processual experience, as a specifically temporal and temporalizing transaction, where human movements in the present are overlayed by technological processes.
\end{abstract}

\section{About the Author}

Timothy Barker is a post-doctoral fellow at the iCinema Research Centre, University of New South Wales, Australia. 


\section{Re-Composing the Digital Present}

\author{
Timothy Barker
}

Consider a late-model car. It is a disparate aggregate of scientific and technical solutions dating from different periods. One can date it component by component: this part was invented at the turn of the century, another ten years ago, and Carnot's cycle is almost two hundred years old. Not to mention that the wheel dates back to Neolithic times. The ensemble is only

contemporary by assemblage.

-Michel Serres, Conversations on Science, Culture, and Time

In Serres' description of the late-model car, we see an image of presentness constituted by a drawing together of, what he terms, the "pleats of time." In essence this is a multitemporal assemblage, taking form in the present. The object that is the late-model car emerges from an aggregate of solutions from different periods in history. In other words, the aggregate of solutions is a grounding from which the present object - and the present moment that is made up of these objects - becomes. What is important to Serres is not the materiality of the late-model car but rather the processes that it embodies, and the way that the object draws together once disparate moments in time into a field of multi-temporality. For Serres, the object or the image, whether this be a car, a book, a thought, or a memory, and likewise every moment in time, is always multi-temporal or polychronic. Like the latemodel car, it is always made up of an aggregate of solutions, concepts or problems originating from different historical eras. Multi-temporal time is a scalar type of time. It has quantity, thick with multiple temporal episodes overlayed in the present, but not a linear direction; it is an archaeological mode of temporality, in which the present moment, the point at which we receive aesthetic information and interact with technology, takes into itself multiple scales of the past.

In this paper, I explore several technologically informed video and interactive works from artists such as Janet Cardiff, Dennis Del Favero, Omer Fast, Grahame Weinbren and the artist group Blast Theory. By investigating the temporality expressed by these works, as they engage with the concept of presentness through digital aesthetics, I provide examples of the way time may be experienced in a similar mode to Serres' multi-temporality. In this argument, the notion of convergence is central, a notion that it must be said has received substantial attention in new media circles, though usually in terms of a convergence of space or a convergence of media objects. Figures such as Lev Manovich, Henry Jenkins, Mark Nunes, and Matthew Fuller have previously pointed out the generative overlay of space and media, which occurs between digital and physical systems at every level of society, expanding the networks and ecological systems formed between people, media systems, and cultures. ${ }^{1}$ For these thinkers, there is a flux of information across the processes, components, and practices of various forms of media. Against this background, this paper attempts to add to this body of theory by exploring the aesthetic consequences of new media

1

Manovich, "The Poetics of Augmented Space," in New Media: Theories and Practices of Digitextuality, eds. Anne Everett and John T. Caldwell (New York: Routledge, 2003), 75-92; Henry Jenkins, Convergence Culture: Where Old and New Media Collide (New York: NYU Press, 2006); Mark Nunes, Cyberspaces of Everyday Life (Minneapolis: University of Minnesota Press, 2006); and Matthew Fuller, Media Ecologies: Materialist Energies in Art and Technoculture (Cambridge, Massachusetts: MIT Press, 2005). 
convergence in terms of time. Of course, the convergence of time and the convergence of space presuppose one another, and it would be quite naïve to think one without the other. Here though, in order to focus on the way that our experience of "presentness" is composed of multiple temporal episodes, I emphasize the role of time, as it is either composed by artists or performed by interacting participants.

\section{The Convergence of Temporalities}

Janet Cardiff's Her Long Black Hair (2004) demonstrates the overlay of actual time by the temporality expressed through a composition of representational and physical processes. In Cardiff's work, participants wear headphones and are lead around New York's Central Park via a pre-recorded voiceover. Occasionally the participants are instructed to stop and inspect a collection of photographs that they have been given. As they hold a photograph up to the scene in front of them, it becomes clear that the participants have been led to the exact spot where the photograph was once taken. Using binaural recording techniques that render a 360-degree sound space mirroring the real world, the walks lead participants around pathways, developing a narrative through the voiceover supplied by the woman with long black hair. She makes observations as we move through the park, accompanied by ambient sounds as well as stories about local histories, which seem to surround the listener and interject at certain points throughout the walk. Putting on the headphones, participants hear footsteps. These are the footsteps of the narrator, and they are told to try and match their footsteps to hers. Later in the work, after instructing participants to turn left along the street, the voiceover tells them that they see peanut sellers, which are not physically present. They also hear dogs barking, getting closer, which again, are not physically present but give the sense that they once were. This aural re-presentation links a contemporary Central Park to historical and fictitious events re-presented, in the sense of making present again. Hence, this work overlays the physical time of the present with the other temporal events narrated through the audio, as we follow the woman's voice through Central Park, taking the same route that she took at the time of its original recording. Through this process of spatio-temporal overlay, Her Long Black Hair creates an augmented type of reality, thickened with two levels of temporality, as the space of the past synchronizes contemporaneously with the space traversed in the present.

What is at stake in the multi-temporality composed by Cardiff is the way histories, both personal and collective, are in constant contact with our experiences of the present moment. The voiceover tells us that "there are always so many layers in front of my eyes," reiterating how layers of the past alter perception and experience in the present. While we navigate through present-day Central Park in cooperation with our virtual tour guide, we hear stories specific to the location such as comments about the polar bears in Central Park Zoo, vignettes from the different neighbourhoods that take the form of excerpts from documentary interviews, or news stories with the testimony of Harry Thomas from the 1850s, a refugee from the slave states who walked across America into Canada. These are supplemented, furthermore, with quotations from other famous walkers such as Charles Baudelaire and Søren Kierkegaard. Interspersed throughout this larger narrative of place that ebbs and flows backward and forward in time, are flashbacks from Cardiff's own experiences while living in New York. At one point Cardiff even shifts from her role as tour guide to answer her cell phone, allowing us to eavesdrop on a short conversation in which she reassures her partner that she is safe in the park at night.

Another example of such an overlay of temporality is Del Favero's Magnesium Light (2009), an installation made up of two video works You and I (2009) and Hold Me (2009). In this two-channel projection, Del Favero sets up an installation space where one part of the work is projected onto a large cinematic screen while the second part is shown on a small screen buried inside a plinth. There is one set of headphones in this installation, and enough 


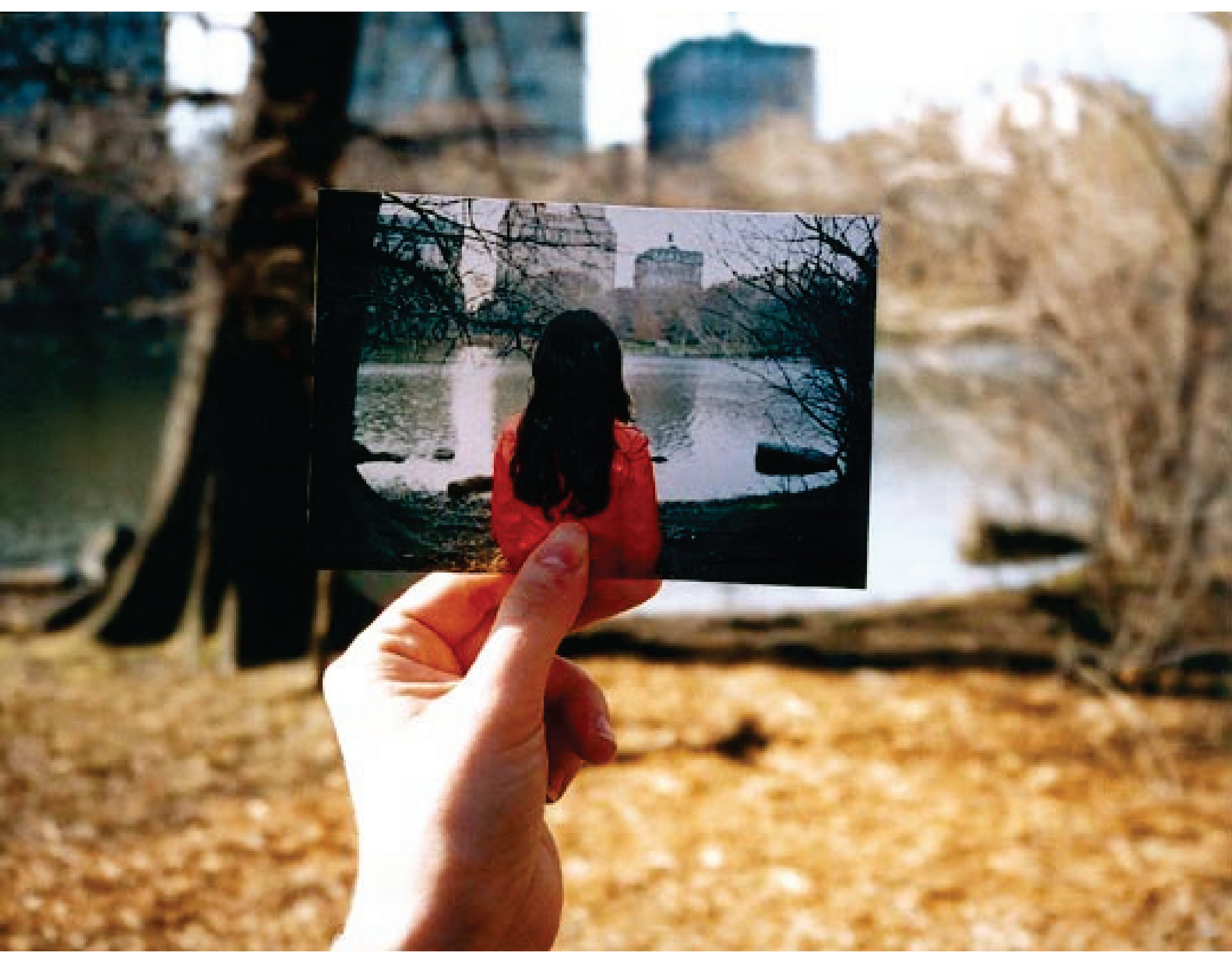

Figure 1

Janet Cardiff, Her Long Black Hair (2004).

Permission to reproduce kindly granted by the artist and Luhring Augustine, New York. 


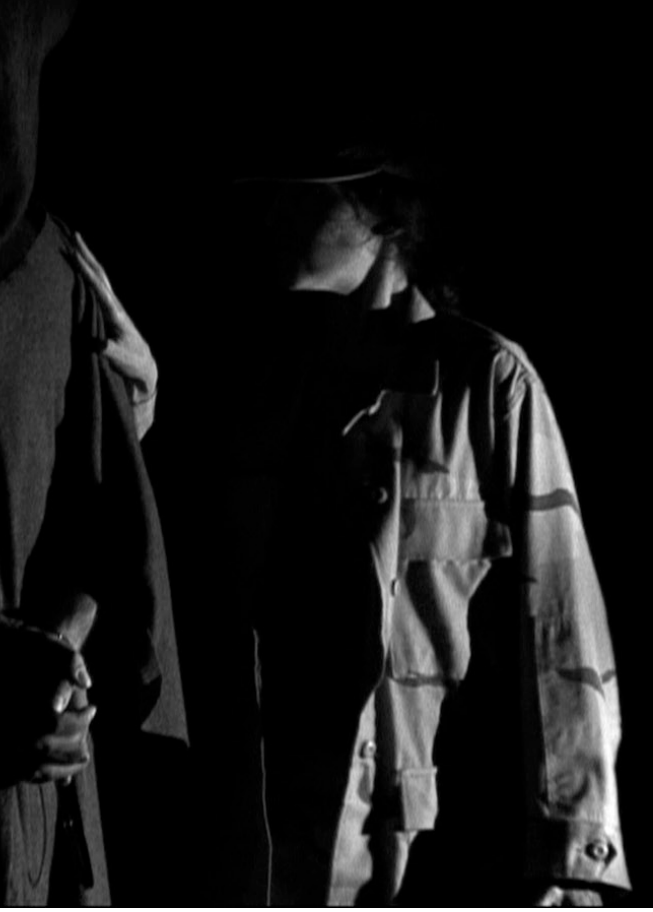

\section{Figure 2}

Dennis Del Favero, You and I, video still (2009).

Permission to reproduce kindly granted by the artist. 


\section{Figure 3}

Dennis Del Favero, You and I, video still (2009).

Permission to reproduce kindly granted by the artist. 
room for a single person to peer into the rectangular cut-out in the plinth, displaying a small and sunken screen. On the large screen, we at first see hands running over a naked female body, passionate scenes of love-making, a couple undressing, and panning close-ups of both the male and female body, sometimes coupled, sometimes alone, as if landscapes set against a black background. We hear a voiceover, a female voice with an American accent, dominated by pleasure and wielding power, which is reiterated in the movement of her naked body projected onto the screen. The voiceover tells us that the actions we are witnessing are not normal; they are the product of the strangeness of the present, an event in which the only people that matter are the two apparent lovers. It is not until toward the end of the relatively short video piece that we become aware of a narrative of rape that has been unfolding through the cascading series of memory-images. We see images of the male with a sack over his head and, more specifically, as the piece ends, we see the woman, wearing army desert fatigues, running her hands over a prisoner, no longer naked and his head again covered by a sack. It is now clear that throughout the piece, the woman attempts to normalize her actions, justifying them through the language of desire, removing herself from the outside world, and repeating "all that matters are you and me." By creating a heroic fiction amidst the alienating context of the Middle East, she attempts to convince herself and her victim that these actions are not as iniquitous as they may seem to an outsider.

As we stand over the plinth and look down at the small screen, we see another perspective from the memory-images shown on the large screen. A male body is the subject of this screen, his hands clutching his face, blocking his sight. Through headphones we hear the voice of the prisoner, attempting to escape the reality of the memories of abuse by repeating a narrative of the last time he was with his wife. In contrast to the audio of the large screen, which attempts to remove the events from the outside world, the prisoner here tries to connect, through memories, to his life outside of this immediate moment. This is the most pointed difference between the two screens, as on the smaller screen the prisoner struggles to escape the traumatic events of the present by remembering the past, and on the larger screen, the soldier's actions and thoughts are caught only in the present, compartmentalized from her past and future.

Due to the layout of the installation, it is impossible to see both screens at once. The process of looking at the small screen, hunched over the plinth, prohibits us from seeing the large screen. Additionally, the prisoner's voice through the headphones blocks out the audio provided by the female voiceover, which otherwise fills the room. This produces two distinct viewing experiences. On the one hand, there is the public experience provided by the cinematic projection, shared with the other viewers, just as the narrative of Abu Ghraib was experienced by most of the world's population through broadcast media images, projected onto the world as the cinematic image is projected into the installation space. On the other hand, there is the personal experience of viewing the small screen, the memories that were not distributed via the media, the narrative and affect that were not experienced by a broader audience. In this part of Magnesium Light, we see the victim's narrative, which, due to the viewing conditions of the space, can only ever be accessed by a few.

In Del Favero's work, which explores traumatic memory - a defining characteristic of his larger oeuvre of video and interactive installations - we experience a singular event of the past through two separate memory-images, as the same event is narrated from two different perspectives. The work is at its most affective when the headphones' audio pauses, allowing one to hear the sound projected into the room that infiltrates the private audio space usually muffled by the headphones. It reminds one of the memory-images on the large screen overhead, which, for the majority of the viewers, dominate the viewing experience. As the audio heard through the headphones pauses, our aesthetic experience in the present is overlayed by two memories from the past, and we are put into contact with the complex temporality of traumatic memory as an oscillation between turbulent private and public memories of the event. 
A similar approach to the aesthetic overlay of temporalities is evident in Omer Fast's The Casting (2007). In this work, we begin to understand the concept of memory, similar to Del Favero's work, as it relates particularly to conflict and trauma. This is a type of memory that is expressed by Fast as a complex of relational stories across disparate geographies and scales of historical time. In Fast's four-channel installation, two double-sided screens hang from the ceiling of an installation space, each with two channels projected back-to-back. Images of actors attempting to remain perfectly still are projected onto the front of these screens, portraying moments of a narrative. These tableaux vivants illustrate two stories from two roads, one in Baghdad and the other in Bavaria, one relating to the accidental, fatal shooting of an Iraqi civilian, the other the journey home after a young man ends a relationship with his self-harming lover. The montage of images consists of American troops pointing their weapons at cars, the aftermath of an exploding roadside bomb, a young redhaired woman arguing with a man in the interior of a car, a domestic scene where a German family stares down an American outsider, and various scenes of American troops driving past Iraqi civilians. A narrating voiceover accompanies these images, providing first-person testimony that shifts erratically from a failed love affair in Germany to combat in Iraq. Moving around the screens, we see that the voiceover is supplied by a young American sergeant, projected onto the back of one screen, in an interview with Fast, who is projected onto the other.

Viewing this footage, it is obvious that the integrity of the original interview has not been maintained. Fast's and the young sergeant's clothes change from moment to moment, and movements, expressions, and sentences are interrupted midstream. To generate the narrative of the work, Fast has spliced and sutured the footage together, treating the original interview recordings as an archived body of data, a bank of words and sentences that are open to his reassembly. From an archive of the sergeant's responses, the two events from different moments in time and geographical locations are edited together, placing these moments in tension and articulating memory-images to create a narrative that was not present in the original dialogue. The Casting thus draws together once historically disparate events in the remixed narrative of the work. Fast has treated memory and history not as a singular whole, but rather as a collection of data similar to Serres' late-model car, capable of being reassembled and reformulated based on a set of organizational structures.

In Fast's, Del Favero's, and Cardiff's works, we see the aesthetic groundings for my use of A.N. Whitehead's concept of temporal thickness, ${ }^{2}$ as elaborated by Deleuze and Serres. These works have been chosen because they each explicitly evoke notions of memory and the temporality of the past, and they each grapple with this temporality differently. The concept of temporal thickness, however, could be applied to an understanding of many other time-based works, particularly those in which a viewer takes on a performative role, involving themselves, in the fullest sense of the term, with images of the past. In works such as these, the present becomes temporally thick as it draws into itself multiple layers of the past and provides the conditions for us to relive this pastness aesthetically. According to Deleuze, a moment may be thought of as temporally thick when the past is drawn into the present. ${ }^{3}$ Furthermore, following Whitehead's earlier process philosophy, we are made acutely aware that every moment has jagged boundaries, always involving itself in our past as well as our future. ${ }^{4}$ As Deleuze states, "the past and the future do not designate instants

\footnotetext{
2 A.N. Whitehead, Process and Reality: An Essay in Cosmology (New York: The Free Press, 1978), 169. First published 1929.

3 Gilles Deleuze, Difference and Repetition (New York: Columbia University Press, 1994), 70-71.

${ }^{4}$ A. N. Whitehead, The Concept of Nature (New York: Cosimo, 2007), 50-55. First published 1920.
} 
distinct from a supposed present instant, but rather the dimensions of the present itself as far as it is a contraction of instants." ${ }^{5}$ In Fast's work, for example, the present narrative is composed of a remix of the past, as the artist reformulates and restructures the original images and sentences. Del Favero likewise composes the events of the past as cascading memory-images, tied together and contracted in the present by two disparate narratives of the same event. The past as a contraction of instants within the present is also presented by Cardiff, whose work links our experience of walking through Central Park in the present to the events of the past that we relive through the audio, rendered in 3D and channelled through the headphones.

The notion of temporal thickness, as it involves the concept of a past that infiltrates the present, necessarily involves questions of memory. For Deleuze, memory is an actualization of the past in the present; it is a reliving of the past based on the conditions from which we remember. He illustrates this by explaining that Marcel Proust's Combray, a place loaded with childhood memories, exists in $\dot{A}$ la recherche $d u$ temps perdu as a past that is remembered not as it was or even as it could be but as a virtual history, as a "...splendour that was never lived." ${ }^{6}$ The hero of $\dot{A}$ la recherche is involved in a process of actively synthesizing information from the past along with data gained from the passive synthesis of the present. Through this act of remembering the past whilst living the present, the hero recollects a time that was never lived but is nevertheless being relived as uncontrolled memories overwhelm him, triggered by the smell and taste of tea and madeleines, in a temporally thick present. This is, of course, similar to the way the past and the present overlay one another in Cardiff's, Del Favero's and Fast's work, as we discover new ways of inhabiting the past in the present.

In order to understand Deleuze's time and the way in which we can use it to understand the types of works already mentioned, we need to examine his conception of a past as an interiority. As Deleuze states, "Time is not the interior in us, but just the opposite, the interiority in which we are, in which we move, live and change." ${ }^{7}$ As such, the past cannot be reduced to an image in the brain, although this may be how it actualizes. It instead exists outside of the mind, with reality, within time, as a non-transcendental field that we must enter in order to locate recollection-images, which are the actualization of this past in the present. My notion of a cumulative past is thus based on my reading of Deleuze, and in particular, his modulation of Henri Bergson's time. In the early part of the $20^{\text {th }}$ century, a period dominated by scientific rationalism, Bergson theorized the primacy of immediate experience and intuition in understanding time and the nature of reality, positioning it as a flow or duration, rather than a series of causally dependent instants. Deleuze uses many of Bergson's famous illustrations of this type of time, and I would like particularly to focus here on the inspiration that Deleuze takes from two of Bergson's images. Firstly, Bergson provides Deleuze with a picture of time as a tape running between two spools, with the past accumulating on one spool and the present passing between the spools. ${ }^{8}$ Secondly, Bergson pictures time as an inverted cone, travelling along a horizontal line. ${ }^{9}$ The point at which the summit of the cone intersects the line is the point at which one experiences an image of the body moving in the present. As we move upward from this present into the wider parts of

${ }^{5}$ Deleuze, Difference and Repetition, 71.

6 Ibid., 85.

7 Gilles Deleuze, Cinema 2: The Time Image (London: Continuum, 2005), 80.

8 Henri Bergson, The Creative Mind (New York: The Citadel Press, 1992), 164.

${ }^{9}$ Henri Bergson, Matter and Memory (New York: Zone Books, 1994), 152. 
the cone we move into the realm of pure memory. Thus, in order for a memory to become actualized in the present, it must descend the cone, moving into the tip and becoming a part of our movement in the present. From these images, Deleuze reads in Bergson a conception of the past that is outside or beyond the mind, as a plane of immanence, a plane "... in which the whole past is entangled and coexists at different levels of expansion and contraction." 10 It is this that enables us to speak of the being of the past and to grant the past a genuine existence.

As Deleuze sets out in Cinema 2, "Bergson's major theses on time are as follows: the past co-exists with the present that it has been; the past is preserved in itself, as past in general (non-chronological); at each moment time splits itself into present and past, present that passes and past which is preserved." 11 If we think in terms of aesthetics, we place ourselves amidst the splitting time, located in the passing present, whilst aesthetic images and processes give form to the preserved past. When we think of the intersection of memory and aesthetics, we think of a bodying forth of pastness via aesthetics in the present. ${ }^{12}$ In Fast's, Del Favero's, and Cardiff's work, aesthetics may express such a concept of the past, drawing it together with the present and entangling memory as the installations embody multiple levels of the past in the present. This facilitates a sensory process that causes us to think, to remember, and to rethink the past.

\section{The Overlay of Processes: Technology and Humans}

In the above examples, I have explored some aesthetic experiments with time, largely structured by narrative content that deals explicitly with memory and its mediation through technological means. However, experiments in media art not only engage time through their content, but also through the interaction with digital technology. When a "user" comes into contact with the tools and aesthetics of digital technologies, she does not simply "use" these technologies in a disinterested manner. Instead the tool reveals itself to be inextricably involved in her experience of the world. ${ }^{13}$ The technology becomes presupposed in the user's sensory experiences; once engaged, it impacts the way she sees, hears, acts and otherwise communicates in the world. Through this process, technology becomes fundamentally temporal as it intervenes in the processes by which we make meaning of the world. It attaches itself to, and affects these processes. ${ }^{14}$

In order to locate the ever-pervasive convergence of humans and technology as a temporalizing process, we could apply the logic of Deleuze and Serres to begin to think about the polychronic events and the unique experience of time that are produced via digital interaction. Beyond the compositionally-generated scalar time set out above, we might think of temporal aesthetics as preceded by an overlay of human and digital processes, as our experience of time is augmented by the process of digital systems.

10 Alia Al-Saji, "The Memory of Another Past: Bergson, Deleuze and a New Theory of Time," Continental Philosophy Review 37, no. 2 (2004), 216.

11 Ibid., 216.

12 Terry Smith, What is Contemporary Art?, (Chicago: University of Chicago Press, 2009), 196-198.

13 Steve Shaviro, "The Universe of Things," Object Oriented Symposium held at Georgia Institute of Technology on April 23, 2010; available at http://www.shaviro.com/Othertexts/Things.pdf.

14 Sean Cubitt, Digital Aesthetics (London: Sage, 1998). 


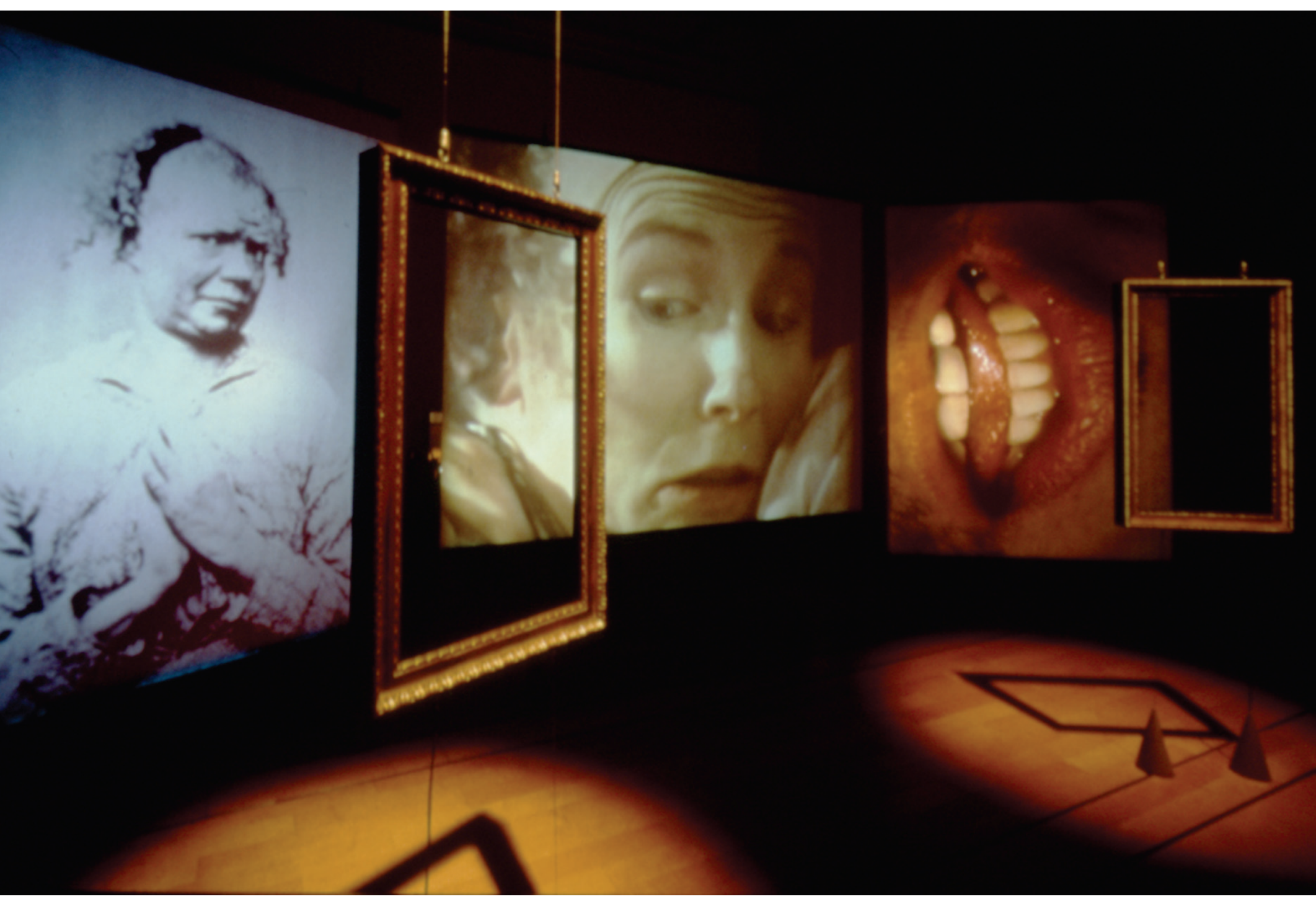

Figure 4

Grahame Weinbren, Frames, detail (1999).

Permission to reproduce kindly granted by the artist. 
A major work from the history of interactive media art that embodies such a notion is Grahame Weinbren's Frames (1999), which uses a database to archive historical photographs as well as contemporary video performances. In Frames, Weinbren appropriates Dr. Hugh Welch Diamond's photographs of mental asylum patients, taken in the 1840s and 1850 s with the recently invented calotype printing technique. Diamond and his colleague John Connolly undertook these photographic sessions in order to evaluate various mental illnesses based solely upon the patient's visual characteristics. ${ }^{15}$ In this sense, the two saw themselves inventing a new diagnostic tool for the field via the technique of photography. In Weinbren's work, a participant stands in front of three large projection screens, two of which are seen through gilded picture frames hanging from the ceiling. Mounted inside the frames are infrared beams, which enable a computer to register the movement of a user gesturing through them. ${ }^{16}$ Standing in front of the screens, the participant sees one of Diamond's $19^{\text {th }}$ century calotypes. If the participant points at the projection, gesturing through the frame in just the right way, she triggers a voiceover taken from an original text that provides the psychiatric description of the patient. Motioning further through the frame, the participant triggers a video of an actor preparing to imitate the poses of the $19^{\text {th }}$ century patient. Making another movement triggers another voiceover, this time a director giving instructions to the actor.

In terms of a temporal aesthetic, we see multiple occasions collected together in the work's database. As source material collected from diverse times, Diamond's photographs, the young actor, and the two different voiceovers suggest different temporalities. The original photograph embodies a historical event, which morphs into the presentness of the young actor performing the photograph and the self-reflexive comments of the director, shaping the actor's future movements. The database draws these occasions together in a new relational context, and Frames invites us to navigate through this data. The past photograph becomes the present, initially composed by the external influence of the director and then later by the interactive movements of a user. We can see here that the database is more than a system associated with the capture and organization of information. Instead it is culturally and temporally significant, as it archives past occasions so that they may be reactualized and re-contextualized in the present.

The temporality of interaction is also central to the aesthetics of this work as, in order to transform the mental patient into the contemporary actor, the participant must regulate her gestures through the frame to a precise temporal rhythm. If she moves too rapidly or too slowly, the images cascade erratically, and the pastness of the photograph does not become the presentness of the actor. Rather the past repeats, unable to progress. The resulting image is a dark staircase - leading the viewer nowhere - perhaps a metaphor for the psychological make-up of the patient. If the participant manages to find the "rhythm" of the piece however, she transforms the image of the mental patient into the moving image of the actor, who now shifts to the center screen and either looks out of a window/mirror or interacts with another fully formed actor in this space. ${ }^{17}$ If the participant successfully moves in the correct tempo, if she is able to tap into the work's "rhythm," she may transform the historical past of the photograph into the present of the actors. However, if she is unable to

\footnotetext{
${ }^{15}$ Grahame Weinbren, Frames, http://www.grahameweinbren.net/frames/FramesICCProp/FramesProp.html, unpaginated.

16 Ibid., unpaginated.

17 Grahame Weinbren, "Ocean, Database, Recut" in Database Aesthetics: Art in the Age of Information Overflow, ed. Victoria Vesna (Minneapolis: University of Minnesota Press, 2007), 79.
} 
find this temporal "rhythm," then the work becomes a repetition of the past and fails to link with the present.

The process of interaction in Frames amounts to a continuation of the past with the present. As a photograph transforms into the image of an actor, a past occasion is shaped into a present one; the present grasps information from the past. In this process, we can understand the past accumulating in Deleuze's non-transcendental field as, following Bergson's image, the tape runs into the spool. This is a field in which the past resides in order to pass information to the present. As the participant gestures through the gilded frames, she triggers past occasions, drawing them forth from an extensive continuum, in this case a database, and activating them in the interacting present. These past occasions direct the present; they provide the conditioning for the present's becoming by providing the images and audio that the user re-assembles in the present.

Both the database of interactive art and the recollection-image of the cinema - famously theorized by Deleuze in Cinema 2 - provide an aesthetic means to relive the past. ${ }^{18}$ Of course by the term "relive" I do not want to imply a simple repetition of the past in an image. Rather, following the Deleuzian rendering of memory cited earlier in this paper, I refer to an actual re-experiencing of these events in the present, in the sense that they are lived again, lived differently, via the archive's preservation of pastness in the present or the cinematic image's actualization of a memory-image. The difference, however, between cinema's and the database's images of the past is that the former re-presents the past in a static way, enabling a viewer to re-think or re-experience the past in a new cinematic time and context. In contrast, interactive art does not just facilitate a re-thinking of the past but rather an actual re-formulation of the past in a dynamic way. It is not so much a past that is seen but rather a pastness that is relived, as physically triggered by the user's actions and capable of being re-organized in the present by the user's agency over the collection of images. The past is not just re-thought here in terms of a cinematic time and space, but in terms of an interacting time and space, shared by both the artistic content and the participant. The user seeks simultaneously to perform and to understand the work in the present. As such, the past is brought into contact with the present as the user is responsible for performing the aesthetics of the work. She re-shapes the past by the act of re-shaping the image of the mental patient, putting the still images of photography from one historical period in relation to the moving video images from a different period. The user thus composes a presentness that takes form as an aggregate of multi-temporal images.

Frames is centered, ultimately, on the relationship between a photographer and his subject, and it is specifically concerned with the ways that technological mediations may in fact produce the subject. Diamond's photographs, for instance, were meant to capture a particular truth about his subject, gaining an insight into the asylum patient's "inner" character. However, his photographs reveal themselves as quite posed. It appears that Diamond himself had instructed the participants to sit, fold their arms, look at the camera manipulating his subject and thus manipulating the photograph and his findings. The interactivity of Frames mirrors this process, with the participant having the power to "shape" the image by gesturing through the frame, by testing out different movements and by finding the correct manner in which to interact with the images.

In a Whiteheadian sense, process here gives form and substance to the aesthetic content of the work. Indeed, the content of the work is shaped by a number of processes: the practice of Diamond posing his subjects in what seem to be painfully unnatural guises; the process of early photography and the long exposure times that made it necessary for

18 Deleuze, Cinema 2: The Time Image, 95. 
subjects to hold their pose; the manner in which the $20^{\text {th }}$ century actors are guided by the director's voice; and the final process of audience interaction with a database. Diamond's original photographs are not of a subject per se, but rather of a subject affected by the processes and conventions of photography. Likewise, the aesthetic experience of Frames does not take form as we receive a set of images in a cinematic sense, but rather as we actively synthesize a set of images affected by the temporality of the database and the "rhythm" of interaction. We can say that the technological mediations at play here are multitemporal in the same sense as Serres' late-model car. The technological operations of the camera, for instance, with its aggregate of parts and inventions such as the lens, the aperture, the discovery of the chemical processes when exposing silver iodide to light, and later the ability of film to reproduce the moving image and its further digitization in the form of video, all date from different historical eras and are all drawn together in the present as pleats of time. It is this overlay of multi-temporal processes that constitutes Frames in the present.

A further example illustrating the relationship between aesthetics, technology, and time is Blast Theory's paradigmatic work Can You See Me Now? (2001). Blast Theory here, as with Weinbren's Frames, explores the temporal processes that emerge as digital systems intervene in our sensory and physical experiences in the world. Using locative and networked media, the performance of a human body is supplemented by technology. Can You See Me Now? takes place in the form of a game that occurs both in the physical setting of the city streets in Sheffield, England and over the Internet in a digitally-generated city. In essence, the Blast Theory performers play a game of catch with online players, as the real life movements of performers on the street are "transcoded" into actions performed in the digital city. Furthermore, actions performed by the online players are translated into the physical world as the Blast Theory performers move around the city, trying to "catch" the online players. Each performer dons a hand-held computer connected to a Global Positioning System (GPS) tracker, which transmits her location through a wireless network to the online players and also shows her the online players' positions in the digital city. ${ }^{19}$ The online players can listen to the walkie-talkie conversation of the runners. Digital and physical processes overlay one another here, as a user moves a character on a computer screen and subsequently interacts with a physical runner on the streets. The artists describe this process, stating:

The experience was perhaps most successful when online players realized that their actions in the online world could affect events in the physical world, for example that the simple act of crossing a virtual line could cause someone to dodge real traffic... One of the most interesting features of the design in this regard is that the online players and runners inhabit separate 'worlds' or environments that are connected together virtually to create what we might call an adjacent reality. ${ }^{20}$

Whilst on the surface this work may appear to be a simple game, it should be viewed in a more complex fashion, in terms of human-technology supplementation, and the manner in which it may direct or constrict a participant's behavior in certain ways. In other words, the technology reveals itself to both significantly empower and restrict the performative ability of the human participants. The performers' physical movements through the city streets are connected to the technology of their hand-held computers, the wireless network, the GPS,

\footnotetext{
19 Steve Benford, et al., "Can You See Me Now?," ACM Transactions on Computer-Human Interaction 13, no. 1 (2006), 100-133.

20 Ibid., 108.
} 
the Internet, and the various online players' computers, all of which empower the runners in the contest of the game. For instance, the hand-held computers tell them where to move in order to catch the online players. However, they are also restricted by this technology. They are unable to move outside of the Wi-Fi network without losing contact with the virtual city and are limited to locations where GPS is available. In some instances, online users would hide behind buildings in known GPS blackspots, where the runners were unable to find them. ${ }^{21}$ The runners in this sense are localized or territorialized by the technology, as it conditions the way they behave.

Can You See Me Now? signifies a process of relationships between technology and the human body. In this process, the human body is directed by the rules and limitations of the digital, as it requires us to act in certain ways, whether this be interaction via a mobile phone network, the Internet, or any other model of interaction. These conditions are presupposed in the way we act in the present. ${ }^{22}$ The networked environment here, following Nunes, both defines and delimits everyday life, as it straddles both informational and physical contexts, with each including and impinging upon the other. ${ }^{23}$ The users must work within the constraints of the locative media; they must remain in the networked area, or work within the software's rules, which restrict the processes that they are able to initiate. We see in this work what Manovich describes as "cellspace," a type of convergent space that exists when an invisible layer of information space, and what we traditionally think of as physical space, augment one another. ${ }^{24}$ In this type of space, synchronised in time, "data flows from the space and into the space," 25 as the digital layer either extracts data from the physical world or enhances it with new data. Presentness in such a mediated environment as the one in Can You See Me Now? or, more generally, in the many contemporary forms of network culture, becomes a condition in which each movement made in the present links to different movements in other locations. Temporality is thick here as the present moment not only involves what is presentationally immediate to our senses - what is here and now - but also as it includes the ever-expanding network and a unison of connected yet geographically dispersed movements in the present.

This paper has provided various illustrations of time and physical processes overlayed, doubled, and thickened via either compositional techniques, such as multi-channel cinematic installations, or via the interactivity of digital systems. In all of these works, we are provided with an opportunity to engage with a temporality beyond a linear sequence of encounters. In this manner, each piece is implicitly processual, as the act of engaging with the work involves some level of physical action, whether this be in the form of walking through Central Park, moving around an installation, or interacting with a database via gestures. As such, the works are performed in the present, and through this performance flow multiple levels of time. The doubling of temporality is actualized in Magnesium Light, for example, as the viewer shifts her gaze from a large-scale cinematic screen to a smaller, more private screen. Likewise, the past is brought into the present in Cardiff's work as we navigate the present directed, literally in this case, by events that occurred in the past. In each work, the digital medium is not merely a means of representing the world. Rather it is a mode of re-

21 Ibid., 114.

22 Adrian Mackenzie, Transductions: Bodies and Machines at Speed (London and New York: Continuum, 2002), 7.

23 Mark Nunes, Cyberspaces of Everyday Life, xi.

24 Lev Manovich, "The Poetics of Augmented Space," 76.

25 Ibid., 76. 
composing the present, of providing a means to rethink the present, to understand it as thick with multiple temporalities. 


\section{(c) EY-NC-ND}

This work is licensed under a Creative Commons Attribution-Noncommercial-No Derivative Works 3.0 United States License.

\section{ULIS D-Surk}

This journal is operated by the University Library System of the University of Pittsburgh as part of its D-Scribe Digital Publishing Program, and is co-sponsored by the University of Pittsburgh Press.. 